\title{
Criminalização das classes subalternas no espaço urbano e ações profissionais do Serviço Social
}

\author{
Criminalization of the subaltern classes in the urban \\ space and Social Work professional actions
}

\author{
Maria Lúcia Duriguetto \\ Professora associada da Faculdade de Serviço Social da \\ Universidade Federal de Juiz de Fora/MG, Brasil; bolsista CNPq. \\ maluduriguetto@gmail.com
}

\begin{abstract}
Resumo: O artigo trata dos processos sócio-históricos da penalização e da criminalização das classes subalternas e de suas formas político-organizativas no contexto das ofensivas do capital à sua crise. Em particular, trataremos das expressões desses processos nas cidades sob as ações do planejamento estratégico e seus enfrentamentos pelas organizações das classes subalternas. Nesse contexto das resistências, evidenciaremos os desafios para o projeto profissional do Serviço Social no espaço das cidades.
\end{abstract}

Palavras-chave: Penalização. Criminalização. Classes subalternas. Movimentos sociais. Planejamento estratégico. Serviço Social.

\begin{abstract}
The article is about the subaltern classes' social-historical penalty and criminalization processes and their political and organizational forms in the context of the offensives of the capital against its crisis. Particularly, we discuss the expressions of such processes in the urban spaces, under the actions of strategic planning and the coping by the subaltern classes' organizations. In this context of resistance, we point out the challenges to the Social Work professional project in the urban space.
\end{abstract}

Keywords: Penalty. Criminalization. Subaltern classes. Social movements. Strategic planning. Social Work.

\section{Introdução}

penalização e a criminalização das classes subalternas e de seus mo-
vimentos e organizações sociais não são fenômenos recentes ou novos.
Ao contrário, são indissociáveis da processualidade histórica do desenvolvimento e expansão do capitalismo e das relações de dominação e exploração que as classes dominantes instituem sobre as classes subalternas. Em suas expressões contemporâneas, tanto a penalização dos "pobres" quanto a crimina- 
lização dos movimentos sociais constituem ações sociopolíticas orquestradas pelos Estados, nas variadas formações socioeconômicas, como respostas às expressões das desigualdades sociais acentuadas pelas ofensivas do capital para recuperação dos processos de sua expansão e valorização. Assim, essas ações são mecanismos de controle e administração das diferentes expressões da "questão social" e das manifestações e resistências populares a elas, que se materializam na criminalização da "pobreza", na judicialização do protesto social, na repressão política aberta e na militarização (Longo e Korol, 2008, p. 46).

Exercer o controle penal sobre os socialmente descartáveis pelo capital e criminalizar as lutas e movimentos sociais é associar pobreza à criminalidade, é transformar a "questão social" em uma questão individual e moral, é deslegitimar as organizações e lutas das classes subalternas, é criminalizar a visibilidade pública e política das expressões da "questão social" e dos sujeitos individuais e coletivos - que reivindicam e/ou defendem direitos, que confrontam a ordem hegemônica capitalista. Neste sentido, não podemos compreender a criminalização da pobreza e dos movimentos sociais apenas por meio das legislações específicas, mas, sobretudo, pela necessidade histórica de sua intensificação para manter a exploração e a dominação do capital.

Neste artigo, pretendemos evidenciar a intensificação dessas ações no contexto das ofensivas do capital à sua crise, bem como algumas expressões contemporâneas da penalização e da criminalização dos sujeitos e das organizações das classes subalternas na particularidade da implementação das diretrizes do chamado "planejamento estratégico" das cidades, que as transformam em polos de atração dos investimentos e de valorização do capital. É nesse contexto que também evidenciaremos as expressões de resistência das classes subalternas e os desafios postos para uma intervenção profissional do Serviço Social em sintonia com o nosso Projeto Ético-Político.

\section{Penalização e criminalização das classes subalternas e de seus processos político-organizativos no contexto da crise do capital}

O controle penal sobre a classe trabalhadora é um fenômeno orgânico ao advento das relações de produção capitalistas, ou seja, foi implementado desde 
a chamada "acumulação primitiva" (Marx, 1985) para conter e punir as chamadas "classes perigosas". ${ }^{1} \mathrm{Na}$ processualidade histórica do desenvolvimento e expansão da acumulação capitalista, tornou-se um fenômeno ineliminável do Estado para a manutenção da exploração e da dominação da burguesia sobre os trabalhadores. ${ }^{2} \mathrm{O}$ uso de medidas punitivas e repressivas foi, assim, desde sua origem marcadamente seletivo e classista, tendo sua base ideológica em determinadas "teorias científicas", que afirmavam e difundiam que o crime é próprio dos estratos mais precarizados da sociedade, como as teorias racistas, das quais o darwinismo social e o movimento eugênico foram paradigmáticas. ${ }^{3}$

No Brasil, a criminalização das classes subalternas é também subjacente às expressões da "questão social", como a pobreza e sua associação à noção de “classes perigosas". Segundo Coimbra (2007, p. 132), desde o final do século XIX, as elites brasileiras construíram a noção da periculosidade com base na concepção de que, "dependendo de uma certa natureza (pobre, negro, semialfabetizado, morador de periferia etc.)", o indivíduo poderia desenvolver atos perigosos e entrar para a criminalidade. ${ }^{4}$

Se esses mecanismos coercitivos estão presentes desde os primórdios do capitalismo, são nas expressões contemporâneas da crise do capital e do

1. A expressão "classes perigosas" foi empregada para se referir, na primeira metade do século XIX, aos trabalhadores não incorporados às novas relações de produção, que Marx denominou de exército industrial de reserva ou superpopulação relativa. Estes tiveram na repressão, na punição e na prisão, as formas de imposição das novas relações de produção (cf. Guimarães, 2008).

2. Os mecanismos coercitivos compõem um dos fundamentos ontológicos do Estado enquanto instrumento de dominação de classe e de manutenção do processo de exploração. Os chamados "aparelhos coercitivos de Estado" (Gramsci, 2000), como as instituições que compõem o sistema de controle penal (policial, judiciária, prisional, dentre outras) se caracterizam pela prevenção ou repressão via aplicação das penas ou medidas de segurança.

3. Essas "teorias", cujo apogeu se deu na Europa da segunda metade do século XIX, defendiam, como as teorias racistas, que as coerções impostas aos negros eram justificadas por sua "natureza", sua "índole preguiçosa e negligente"; já o eugenismo combatia as misturas raciais por produzirem seres inferiores moral e fisicamente e, portanto, potencialmente perigosos. Nessa perspectiva, tem-se a naturalização da relação entre pobreza e criminalidade, na qual todo pobre é considerado criminoso e vice-versa (cf. Coimbra, 2001).

4. Essas construções ideológicas sedimentaram, no final do século XIX e início do XX, o desenvolvimento do chamado Movimento Higienista, que pregava "o aperfeiçoamento da raça, colocando-se abertamente contra negros e mestiços" (Coimbra, 2007, p. 135). O conjunto dessas teorias serviram de base para a construção de ações públicas segregacionistas do espaço urbano, em que os territórios de adensamento quantitativo de pobres e negros precisariam ser erradicados para longe da visibilidade urbana e "civilizada", condição para a garantia da "ordem social", da "segurança" e da "salubridade". 
conjunto das ofensivas em curso para a retomada de sua expansão que temos a intensificação dos processos de controle penal do Estado, em especial sobre a força de trabalho excedente. Passemos, agora, a uma sumária explicitação de alguns elementos que conformam a dinâmica dessa crise.

Segundo Mandel (1990), a dinâmica capitalista se desenvolve ciclicamente em ondas longas de expansão e de retração (ou depressivas), de acordo com o aumento, a queda e a revitalização da taxa de lucros. $\mathrm{Na}$ fase do capitalismo monopolista, a valorização do capital se materializou na consolidação de um novo padrão de acumulação — sustentado no binômio taylorismo-fordismo — e de um novo regime de regulação social — amparado no desenvolvimento dos modelos dos chamados Estados de bem-estar. Esse binômio passa a configurar a dinâmica econômica e sociopolítica nos países centrais do segundo pós-guerra. No início da década de 1970, o declínio do crescimento econômico, a queda das taxas de lucro e o desemprego foram indícios da saturação daquele padrão de acumulação e regime de regulação, vindo a se manifestar em uma crise estrutural do capital. ${ }^{5}$ Para Antunes (1999, p. 29-31), os elementos constitutivos mais essenciais dessa crise podem ser identificados: na queda da taxa de lucro, dada, entre outros elementos, pelo aumento do preço da força de trabalho e pelo avanço das lutas sociais - o capital atribui às conquistas do movimento sindical a responsabilidade pelos gastos públicos com as garantias sociais e a queda das taxas de lucro às suas demandas salariais; no esgotamento do padrão de acumulação taylorista-fordista de produção decorrente da retração dos níveis de consumo, produto do desemprego estrutural que então se iniciava, hegemonia do capital financeiro e dos mecanismos especulativos de acumulação; na maior concentração de capitais graças às fusões entre as empresas monopolistas e oligopolistas.

Desde o último terço do século XX, essas dimensões da crise estrutural do sistema do capital impulsionaram as grandes corporações mundiais e os

5. Na análise de Mészáros, "o sistema de metabolismo social do capital vem assumindo cada vez mais uma estruturação crítica profunda. Sua continuidade, vigência e expansão não podem mais ocorrer sem revelar uma crescente tendência de crise estrutural que atinge a totalidade de seu mecanismo. Ao contrário dos ciclos longos de expansão alternados com crises, presencia-se [hoje] um depressed continuum que, diferentemente de um desenvolvimento autossustentado, exibe as características de uma crise cumulativa, endêmi$c a$, mais ou menos uma crise permanente e crônica, com a perspectiva de uma profunda crise estrutural" (Antunes, 1999, p. 27; grifos do autor). 
bancos multilaterais de financiamento a buscar saídas para renovar a valorização do capital e restabelecer suas taxas de lucro. Restabelecer as taxas de lucro implica intervir nos mecanismos de exploração da força de trabalho e nas suas condições de reprodução. Assim, o processo de "restauração capitalista" assenta-se nas seguintes ofensivas (relacionadas entre si e interdependentes) implementadas nas diversas economias mundiais a partir da década de 1970 e, no Brasil, mais precisamente a partir da década de 1990: reestruturação dos processos de acumulação, expresso na chamada acumulação flexível (Harvey, 1993); mundialização da economia — nova divisão internacional do trabalho com hegemonia do capital financeiro; imposição do projeto neoliberal e seu decorrente receituário de ajuste das políticas econômicas e sociais na esfera do Estado.

Destacamos, no âmbito das mudanças na esfera produtiva, a precarização das condições e relações de trabalho, que têm na flexibilização da contratação, uso e dispensa da força de trabalho, bem como no fenômeno do desemprego estrutural, uma das suas faces mais expressivas. No que tange às políticas de ajuste neoliberais, destacamos as contrarreformas implementadas na área social, cujo foco é a redução dos recursos orçamentários que compõem o fundo público para as políticas sociais e o fortalecimento da expansão das relações contratuais mercantis na sua oferta. No Brasil, esse receituário, implementado a partir da década de 1990, expressa-se, entre outras ações, no fomento e na indução à privatização de políticas e serviços sociais, na expansão das parcerias público-privadas, das organizações sociais, das políticas compensatórias, em particular, as de transferência mínima de renda, que tem na assistencialização a sua expressão central (Mota, 2008).

Compõe esse cenário regressivo as medidas punitivas e repressivas estatais, que vêm assumindo uma crescente e contínua predominância na administração das desigualdades e, também, das resistências que a elas são organizadas pelos trabalhadores. Essas desigualdades — resultantes da dinâmica contemporânea de acumulação do capital e das suas ofensivas explicitadas anteriormente são disseminadas, tal qual no século XIX, como problemas de ordem individual e moral. É sob essa ideologia que se reveste a contenção e a administração pelo cárcere, pela assistencialização ou pelo extermínio dos "pobres", dos desempregados, do precariado, dissipando-se, assim, "qualquer vínculo entre 
delinquência e desemprego, insegurança social, escalada dos distúrbios públicos e aumento das desigualdades" (Wacquant, 2001, p. 60).

Em relação ao encarceramento, como evidencia Wacquant (2007) - ao analisar a decadência do chamado Estado caritativo estadunidense, em que a " "guerra contra a pobreza' foi substituída por uma guerra contra os pobres" em todas as economias mundiais se opera a expansão da privatização do sistema prisional, particularmente por meio de formação de parcerias público-privadas, aumento da contratação de agentes policiais pelo Estado, bem como a constituição de uma política criminal pautada no discurso da tolerância zero, que é punir com rigor os pequenos desvios para extinguir o crime desde seu início. Essas ações também vêm se constituindo em um negócio lucrativo, tanto pela privatização do sistema prisional quanto pelo mercado de segurança social — indústrias de segurança e produtos. ${ }^{6}$

O discurso ideológico do medo do outro fortalece o clamor popular pelo recrudescimento do controle punitivo do inimigo social - o jovem, pobre, negro e desempregado e cooptado pela economia ilegal do tráfico de drogas, que se transpõe nas ações diretas de extermínio executado ou não em nome da lei ${ }^{7}$ e/ou de discursos ideológicos que levam a conceber a pobreza como ameaça e a impregnar esses sentimentos com "conteúdos racistas, xenófobos, violentos, repressivos e autoritários", como a defesa da política da tolerância

6. Nas últimas décadas do século XX, o encarceramento cresceu em todas as economias mundiais. Nas Américas, foi superior a $80 \%$, e em países em via de desenvolvimento, como África e Ásia, foi acima de $100 \%$. Segundo Pavarini, é possível arriscar que a cada ano, entre 30 milhões e 50 milhões de pessoas experimentam uma experiência detentiva no mundo (apud Ramos, 2015, p. 137-138). No Brasil, o relatório do Sistema Integrado de Informações Penitenciárias, o Infopen, que reúne dados do encarceramento até junho de 2014, revela um crescimento de $161 \%$ no total de presos desde 2000 , o que o coloca em terceiro lugar do mundo em encarceramento. O que se tem evidenciado não é o aprisionamento de criminosos violentos, mas das camadas mais pauperizadas, dos desempregados, em especial os jovens, que representam $54,8 \%$ da população carcerária. Em sua maioria os atos ilícitos cometidos são "ofensivos ao patrimônio" ou relacionados a drogas e foram praticados por jovens de 18 a 21 anos (cf. Mapa do encarceramento — os jovens do Brasil, 2015).

7. No Brasil, os homicídios são a principal causa de morte de jovens de 15 a 29 anos e atingem especialmente negros, moradores das periferias e áreas metropolitanas dos centros urbanos. Dados do Sistema de Informação sobre Mortalidade (SIM)/Datasus, do Ministério da Saúde, mostram que mais da metade dos 56.337 mortos por homicídios em 2012 no Brasil eram jovens (27.471, equivalente a 52,63\%), dos quais $77 \%$ negros (pretos e pardos) (cf. Mapa do encarceramento — os jovens do Brasil, 2015). 
zero, da redução da idade penal, das torturas em cárceres e delegacias, das batidas e detenções arbitrárias e da militarização dos territórios (Longo e Korol, 2008, p. 48).

Não é só a hipertrofia da ação repressiva do Estado burguês que quer dar conta da população excedentária. Ela conjuga-se com outra dimensão, coesiva e legitimadora: o novo assistencialismo. De acordo com Netto (2012, p. 428; grifos do autor), "a política social dirigida aos agora qualificados como excluídos [...] não tem nem mesmo a formal pretensão de erradicar a pobreza, mas de enfrentar a penúria mais extrema, a indigência [...] a pobreza absoluta". Isto tem caracterizado os vários programas que, por via de transferências de renda, têm sido implementados em alguns países capitalistas centrais e em muitos periféricos.

O caráter jurídico-político da criminalização dos movimentos sociais também se acentua no contexto de implementação das medidas ofensivas do capital para a sua valorização. É nesse contexto que ganha força um novo momento de criminalização da "questão social", que toma forma na judicialização dos conflitos sociais e na criminalização dos processos de organização e de lutas das classes subalternas. ${ }^{8}$ Em outras palavras, a judicialização dos conflitos e das lutas sociais é uma das formas que as frações das classes dominantes vêm utilizando, de maneira intensa, para ocultar a lógica conflitiva da luta de classes visibilizada, pública e politicamente, pelas classes subalternas e seus processos político-organizativos de lutas. Ao transportar o conflito e as lutas para as arenas judiciais, o instrumento mormente usado para criminalizá-los é o da garantia legal do direito de propriedade. Nessas arenas, o Poder Judiciário exerce uma das suas principais funções, que é a de se constituir no instrumento de legitimação do exercício do poder coercitivo do Estado, utilizando-o para criminalizar e deslegitimar as lutas e os movimentos sociais.

Associada à criminalização dos movimentos sociais temos, como exposto acima, a também histórica associação entre pobreza e criminalidade, o que reforça a ideia de que as ações realizadas pelos movimentos sociais (como os

8. Experiências de criminalização dos movimentos sociais em países como Argentina, Brasil, Chile, México estão, por exemplo, em Buhl e Korol (2008). 
sem-terra, sem-teto, que são compostos por pobres e, na maioria, negros), correspondem a delitos, a atos criminosos.

Nesse contexto de crise do capital, há alguma novidade no processo de criminalização dos movimentos sociais na conjuntura brasileira? Para Sauer (2008), a resposta depende da compreensão do que seja "criminalização", pois se o conceito se ater às formas de violência (uso da força bruta), ameaças e perseguição aos movimentos sociais e suas lideranças (assassinatos, ameaças de morte, intimidações, despejos etc.), não há muita novidade. Mas se operarmos uma distinção conceitual entre violência e criminalização, identificaremos novas determinações aos processos contemporâneos que, segundo Sauer (2008, $\mathrm{s} / \mathrm{p})$, podem ser notadas nas

ações de diferentes aparelhos de Estado (Parlamento, Judiciário, Ministério Público, Tribunal de Contas da União ${ }^{9}$ - TCU) que, utilizando mecanismos e instrumentos legais e/ou constitucionais, conferem caráter de crime às ações e lideranças populares. Consequentemente, criminalizar não é utilizar a força policial para reprimir manifestações (tratar como "caso de polícia”), mas é transformar (caracterizar ou tipificar) uma determinada ação em um crime. Utilizando mecanismos legais, a intenção é fazer com que ações e pessoas sejam vistas e julgadas (pela opinião pública, pelo órgão estatal responsável) como atos criminosos e bandidos. Não há qualquer dúvida que essa ação pode ser classificada como uma violência, mas a prática da criminalização é um aprimoramento e uma sofisticação dessa violência.

De acordo com Sauer (2008), o que essas ações evidenciam é uma substituição, ainda que não exclusiva, das ações violentas ${ }^{10}$ por "mecanismos mais

9. As ações do TCU funcionam como um mecanismo para impedir ou para limitar o repasse de recursos públicos para entidades populares e movimentos sociais. Essa lógica funciona como um mecanismo de criminalização (acusação de desvio ou malversação de recursos públicos), mas também como uma forma de pressão sobre o Executivo federal, evitando o repasse e imobilizando muitas ações e/ou movimentos. Nesta direção, por exemplo, foi criada em 2009, no Legislativo, a Comissão Parlamentar de Inquérito sobre o Movimento dos Trabalhadores Sem Terra (MST).

10. O uso ostensivo da força policial e militar é recorrente para ações em favelas, territórios indígenas e nas manifestações de protestos de rua, como, por exemplo, as de junho de 2013. É digno de nota as ações 
sofisticados de repressão das demandas sociais". ${ }^{11}$ Essa sofisticação jurídica evita rejeições da opinião pública como abusos de poder (uso violento de força policial), e a acusação de crime deslegitima as reivindicações e os sujeitos que as portam, transformando as primeiras em ilegais e os segundos em "criminosos". Há que se reconhecer, ainda, que essa sofisticação da criminalização é fortalecida pela ação dos meios de comunicação, que priorizam as falas criminalizatórias e manipulam as informações e os fatos referentes às manifestações e lutas sociais.

É nesse contexto de judicialização dos protestos sociais que surge a lei antiterrorismo, a qual emerge num contexto de retomada de grandes mobilizações de massas nas ruas. ${ }^{12} \mathrm{O}$ projeto inicial, o PL n. 2.016/2015, de autoria do Poder Executivo, tipificou o crime de terrorismo na legislação brasileira ${ }^{13}$ e não enquadrava na lei a conduta individual ou coletiva de movimentos sociais, sindicais, religiosos, de classe ou de categoria profissional se eles tivessem como objetivo defender direitos, garantias e liberdades constitucionais. ${ }^{14}$ No entanto, as práticas

violentas utilizadas contra os moradores da ocupação do Pinheirinho, no município de São José dos Campos (SP), em 2011.

11. Um exemplo foram as tentativas judiciais do conselho de promotores do Rio Grande do Sul, em 2008, voltadas para criminalizar as atividades do MST, como a proibição de suas marchas e de impedir a sua existência, sob o argumento de ser uma organização terrorista.

12. Exemplo das jornadas de junho de 2013; da criação de vários comitês populares da Copa, das lutas e resistências indígenas, dos movimentos feministas; dos movimentos urbanos, em particular os de luta pela moradia.

13. O governo justificou a iniciativa para a criação da lei pela necessidade de atender a compromissos internacionais firmados pelo Brasil com o Grupo de Ação Financeira contra a Lavagem de Dinheiro e o Financiamento do Terrorismo (Gafi/FATF). O Gafi é uma entidade intergovernamental criada em 1989, que tem como função promover regulamentações para combater a lavagem de dinheiro e o financiamento do terrorismo, cuja implementação deve ser avaliada pelo Fundo Monetário Internacional (FMI) e pelo Banco Mundial (BM). Tais avaliações impõem sanções que podem afetar o "grau de investimento" em países que não têm legislações contra o terrorismo. Ver: FATF-Gafi (2012), disponível em: <http://bit.ly/liLpkqC> Acesso em: 20 jan. 2016. No entanto, “dos 193 países em que hoje se divide o mundo, apenas cinco definem penalmente o terrorismo. Não por acaso, a ONU já examinou mais de 150 propostas de definição de terrorismo, rejeitou todas, e não recomenda que os Estados que a integram o façam em suas legislações" (Pilatti, 2016, s/p). Foi também num contexto de ascenso de lutas por direitos que essa lei foi aprovada na Argentina em dezembro de 2011, cuja justificativa para a sua tramitação acelerada no Senado e na Câmara foi os Estados Unidos e o Gafi exigirem a sua aprovação sob ameaças de aplicar sanções econômicas, as quais consistiam na não concessão de créditos por parte do BM, FMI e outras entidades internacionais (Buhl e Korol, 2008, p. 73).

14. Em agosto de 2015, a Câmara aprovou um texto-base que tipificava as ações terroristas, mantendo a exclusão da conduta individual ou coletiva de movimentos sociais, organizações sindicais e movimentos 
definidas como terroristas possibilitam uma larga margem de subjetividade à autoridade policial, ao Ministério Público e ao juiz, uma vez que serão eles que dirão se o ato delituoso foi cometido com propósito social ou reivindicatório e, assim, será enquadrado segundo o Código Penal, ${ }^{15}$ ou se foi cometido com propósito terrorista" (Pilatti, 2016, s/p). Então, mesmo com a ressalva, não se impede a criminalização, porque o julgamento sempre dependerá do filtro ideológico desses atores jurídicos, muitos dos quais veem na atuação de alguns movimentos sociais uma ofensa à Lei de Segurança Nacional. ${ }^{16}$

A análise desses processos contemporâneos de penalização e criminalização das expressões individuais e coletivas das desigualdades sociais e dos seus enfrentamentos pelas classes subalternas, para além da explicitação das determinações macrossocietárias das ofensivas do capital e do Estado nos marcos conjunturais da crise, exige estudos e análises de cada fenômeno na sua particularidade. Nesta direção, nos deteremos, a seguir, em algumas caracterizações da ofensiva para a valorização e reprodução do capital no âmbito das cidades e de sua associação ao binômio penalização-criminalização das frações mais precarizadas das classes subalternas.

\section{Planejamento estratégico: a cidade como mercadoria}

No contexto das ofensivas do capital sob a égide das políticas neoliberais de enfrentamento à sua crise, são centrais as diretivas presentes no que Chesnais

reivindicatórios que objetivam defender direitos, garantias e liberdades constitucionais. O projeto foi posteriormente substituído no Senado pelo Projeto de Lei Complementar (PLC) n. 101/2015, no qual foi retirada a ressalva incluída pela Câmara. O texto retornou à Câmara, que restabeleceu o texto anteriormente aprovado, sendo este o sancionado pelo Executivo federal em março de 2016 (Lei n. 13.260/2016). Disponível em: $<$ http://www.planalto.gov.br/ccivil_03/_Ato2015-2018/2016/Lei/L13260.htm>. Acesso em: 20 jan. 2016.

15. As condutas tipificadas como crimes de terrorismo são, em sua maioria, tipificadas como crimes comuns. Também na Argentina, a ambiguidade "na tipificação do que é um ato de terrorismo abre as portas para considerar terrorista qualquer um que se oponha às políticas governamentais e decida militar ativamente contra elas. Em poucas palavras, torna-se uma desculpa perfeita para a perseguição política" (Buhl e Korol, 2008, p. 74).

16. Lei n. 7.170, de 14 de dezembro de 1983, que define os crimes contra a segurança nacional, a ordem política e social e estabelece seu processo e julgamento. Disponível em: $<\mathrm{http}: / /$ www.planalto.gov.br/ccivil_03/ leis/17170.htm>. Acesso em: 20 jan. 2016. 
(1996) define como mundialização da economia e ao seu imperativo de funcionalidade à acumulação e à internacionalização do capital, que vem implicando restrições crescentes à soberania e à autonomia dos Estados nacionais. ${ }^{17}$ Como nos esclarece Chesnais (1996, p. 34), a palavra de ordem é que as sociedades se adaptem "às novas exigências e obrigações e, sobretudo, que descarte qualquer ideia de procurar orientar, dominar, controlar, canalizar esse novo processo". A necessária adaptação pressupõe liberalização e desregulamentação para o livre movimento das forças do mercado "e que todos os campos da vida social, sem exceção, sejam submetidos à valorização do capital privado" (Chesnais, 1996, p. 25).

São nessas condições gerais postas pela mundialização que se impõem as diretivas para as escalas nacional/regional/local se adequarem à funcionalidade de reprodução e acumulação do capital. Em particular, as cidades passam a ser concebidas como polos centrais de atração de investimentos e de desenvolvimento econômico. A obtenção desse "certificado" para a entrada de investimentos seria possibilitada pelo planejamento de ações estratégicas voltadas para torná-las atrativas para o capital Duriguetto (2004). É essa diretiva que substantiva os manuais do chamado planejamento estratégico, como evidencia Vainer (2000). Nas palavras de Borja (1997, p. 89), um dos mais importantes ideólogos desse projeto de cidade, o governo local deve promover a cidade para o exterior, "desenvolvendo uma imagem forte e positiva, apoiada numa oferta de infraestruturas e serviços (de comunicações, econômicos, culturais, de segurança etc.) que atraia para a cidade investidores [...]". O planejamento estratégico das cidades é, assim, pensado e desenvolvido ante os ditames da mundialização, que subordinam as cidades à criação de instrumentos voltados para incrementar sua competitividade e para ofertá-las no mercado global, que integre a organização dos espaços urbano-regionais e os investimentos públicos nos circuitos de valorização do capital e de atratividade para os grupos econômicos privados. Assim, o planejamento estratégico é um projeto de cidade já precon-

17. Isso não implica que se deva concluir que a era do Estado-nação acabou, pois não apenas os Estados continuam sendo centrais para o próprio avanço da mundialização da economia (ao elaborar ou somente implementar as diretrizes postas pelas suas forças dominantes), como também permanecem diferenças e particularidades nas realidades nacionais, que geram variações na implementação daquelas diretrizes. 
cebido imposto pela crise; é a apropriação direta do poder público e da cidade pelos interesses do capital internacional e nacional (cf. Vainer, 2000).

No Brasil, essa ideologia da cidade vendável é particularmente presente na conjuntura dos megaeventos esportivos, como na Copa do Mundo em 2014 e das Olimpíadas em 2016. Para a realização desses eventos, o Rio de Janeiro ${ }^{18}$ se tornou uma cidade em que o poder público garantiu a valorização do capital por meio de legislações de isenções e favores fiscais e urbanísticos. ${ }^{19}$ É nesse contexto que vem se configurando a prática de criminalização dos moradores que habitam áreas estratégicas para a valorização do capital bem como de suas resistências, que podem ser evidenciadas nas ações das remoções. O caráter abusivo e arbitrário das remoções é evidenciado, de acordo com Mattos (2013, p.180-181), na chegada repentina de equipes de demolição, sem qualquer aviso prévio para que os moradores providenciassem outra moradia ou a remoção adequada dos seus pertences; emprego de táticas violentas e intimidantes, como o acionamento da polícia militar para lançar bombas com gás de pimenta contra moradores resistentes; retirada de pessoas sem o recebimento de habitação alternativa e/ou indenização justa; realização de remoções com base em justificativas contestáveis, como as de definição de área de risco. ${ }^{20}$ Destaca-se, nesse contexto, as massivas ordens de despejo feitas pela Procuradoria Geral

18. Vainer (2000) explicita, já na elaboração do plano estratégico da cidade do Rio de Janeiro em 1993 e 1994, essa ideologia mercantil da cidade.

19. Alguns desses "favores" podem ser conhecidos em Santos Júnior (2016).

20. Como explicita Magalhães (2015, s/p), a Lei Orgânica Municipal da cidade do Rio de Janeiro, em seu artigo 429, proíbe as remoções, a não ser em casos muito específicos, e devem estar justificadas em laudo técnico e envolver a participação direta dos moradores. No entanto, na prática de remoções "prevalece todo tipo de dispositivos de exceção", em que se destacam "as práticas de pressões diárias, tais como aquelas feitas por agentes públicos quando dizem aos moradores: 'ou você aceita a 'proposta' ou vai ficar sem nada', 'se não aceitar, vai para a rua', [...]; há um intenso esforço de fazer com que os próprios moradores entrem em conflito entre si, através da manipulação da informação sobre a situação local (informações conflitantes são repassadas a cada um); a emissão de autos de interdição (alegando risco) sem especificação e exigindo saída imediata, sem alternativa; a falta de identificação, por parte dos moradores, dos agentes com os quais são obrigados a lidar nestas situações; espalhar, a partir de contatos individualizados, que a prefeitura conseguiu liminares e que a qualquer momento pode ocorrer o despejo [...]; para evitar resistências, agentes do Estado afirmam que irão resolver a situação particular de cada um, solução esta que nunca chega [...]; falta de acesso aos projetos a partir dos quais as remoções são justificadas; demolições sem compensação financeira; a destruição de casas geminadas como forma de pressão; e cortar ou limitar o acesso a serviços públicos, como água e eletricidade". 
do município, o que revela "a seletividade classista do sistema judiciário", bem como as chamadas "remoção branca" ou "remoção via mercado", em que os moradores não têm condições de pagar suas contas devido à especulação imobiliária, principalmente nas favelas ocupadas pelas Unidades de Política Pacificadora (UPPs) a partir de 2008. Essas ações tornam "cada vez mais evidente o objetivo de expulsão dos pobres das áreas valorizadas ou que serão contempladas com investimentos públicos" (Mattos, 2013, p. 182).

Uma nova escalada da criminalização é adicionada à prática da remoção e dos despejos, que é a acentuação da intervenção estatal em seu aspecto penal com as UPPs. Estas “promovem uma regulação armada dos territórios estratégicos para a realização desse modelo empresarial de cidade impulsionado pelos megaeventos", ${ }^{21}$ reatualizando tanto a "vocação secular do Estado brasileiro para tratar a questão social como "caso de polícia"'22 (Brito, 2013, p. 99), quanto as bases ideológicas das teorias racista e eugênica e suas associações entre "pobreza" e "delito". Essas duas reatualizações são coroadas pela acentuação da face penal do Estado caracterizada, aqui, pela substituição da formulação e operacionalização de políticas públicas para o combate às desigualdades pela política de repressão. ${ }^{23}$ Assim, a política pública é transmutada em política de segurança pública.

A instalação das UPPs, para além da criminalização dos moradores de suas áreas de ação, também criminaliza pela repressão e intimidação sujeitos que — individual ou coletivamente — realizaram ou realizam denúncias sobre as violações de direitos produzidas pelos agentes policiais, como coletivos que trabalham com mídia comunitária (seja rádio ou jornal), movimentos sociais de favelas e de atuação no campo de defesa dos direitos humanos.

21. Como evidencia Brito (2013, p. 97), "basta observar os mapas das UPPs para constatar a instauração de um 'corredor de segurança' nas áreas diretamente envolvidas na realização dos Jogos Militares, da Copa das Confederações, da Copa do Mundo, dos Jogos Olímpicos etc.”.

22. A militarização de determinadas áreas de interesse para os megaeventos simboliza a possibilidade de que, "em nome da conservação da ordem social, sejam instituídas zonas despojadas de direito - ou 'estados de exceção' onde prima uma pura lógica de ação policial” (Gargarella e Svampa, apud Longo e Korol, 2008, p. 52-53).

23. Segundo Brito, Villar e Blank (2013, p. 235), "o dispêndio da União com segurança pública cresceu $202 \%$ entre 2003 e 2009, enquanto as despesas dos estados e do Distrito Federal no mesmo período aumentaram 96\%". 
Essa lógica mercantil que determina a ideologia do planejamento estratégico e a criminalização social que a acompanha tem, nas organizações e movimentos sociais das classes subalternas os seus oponentes, posto que são os sujeitos que a enfrentam e resistem a ela. No tópico seguinte, evidenciaremos algumas expressões desse universo político-organizativo para nele tratar de alguns desafios postos para o projeto profissional do Serviço Social.

\section{A cidade em disputa: organizações e movimentos sociais das classes subalternas e o projeto profissional do Serviço Social}

Formas significativas de resistência das classes subalternas - por meio de organizações, movimentos sociais, coletivos e fóruns - foram criadas, especialmente a partir da década de 1980, na realidade brasileira em torno de demandas e políticas circunscritas no âmbito da chamada reforma urbana. ${ }^{24}$ Destacamos a constituição, em 1985, do Movimento Nacional pela Reforma Urbana - primeiro movimento de âmbito nacional relativo ao direito à cidade - que teve papel fundamental para a instituição, na Carta de 1988, de um capítulo sobre a política urbana; o Fórum Nacional de Reforma Urbana (FNRU), criado em 1987, que reúne diferentes movimentos e entidades, entre as quais o Conselho Federal de Serviço Social - e que teve uma atuação fundamental para a promulgação do Estatuto da Cidade; ${ }^{25}$ organizações e movimentos de âmbito nacional que priorizam sua visibilidade pública e política na ação direta (ocupações), como o Movimento dos Trabalhadores Sem Teto (MTST), que integra a Frente de Resistência Urbana; organizações, fóruns, frentes, coletivos e movimentos sociais presentes em diversos estados ou em âmbitos locais, que atuam por demandas relativas às políticas públicas urbanas, como saúde, cultura, habitação, meio ambiente, transporte etc.; como o Movimento Passe Livre (MPL); a constituição dos Comitês Populares da Copa (no caso do Rio de Janeiro, foi constituído o Comitê Popular da Copa e das Olimpíadas)

24. Amparo, aqui, na sistematização realizada por Farage (2014).

25. Promulgação que acontece tardiamente em 2001, regulamentando o capítulo da política urbana da Carta de 1988. 
e da instância que os agrega - a Articulação Nacional dos Comitês Populares da Copa (Ancop).

É nesse contexto de lutas, de organizações e movimentos que disputam a cidade, aberto especialmente a partir dos finais dos anos 1970, que se situa muito dos conteúdos teórico-metodológicos e ideopolíticos do projeto profissional do Serviço Social brasileiro para a prospecção de uma intervenção profissional sintonizada com as demandas das classes subalternas pelo chamado "direito à cidade". Destacamos, aqui, alguns desses indicativos presentes na produção de conhecimento; nas sistematizações interventivas de segmentos profissionais e nos posicionamentos político-interventivos das organizações da nossa categoria:

- Combater apreensões setorializadas das desigualdades sociais que se expressam na chamada "questão urbana" - como a questão da moradia, da saúde, do saneamento, do transporte etc., bem como a defesa de sua apreensão totalizante e tratamento transversal nas políticas públicas e na garantia dos direitos.

- Romper com uma visão moralizante e individualizante das expressões das desigualdades sociais e não compactuar com ações arbitrárias e ilegais como as remoções e intervenções forçadas.

- "Intensificar a luta pela não subordinação do trabalho técnico social aos interesses econômicos; a definição sobre o fazer profissional é ação privativa do Serviço Social" (Farage, 2014, p. 260).

- Contribuir com a solidariedade às vítimas imediatas desses processos de criminalização, pois lidamos, em muitos dos nossos espaços sócio-ocupacionais, com mulheres que perdem seus filhos pela ação do extermínio ou pelo encarceramento; jovens, particularmente negros e negras, que são espancados e/ou molestados sexualmente em abordagens policiais ou detidos de forma arbitrária; coletivos, movimentos e organizações comunitárias - como de mídia, de reivindicações de direitos ou de denúncia - que sofrem ameaças e perseguições para silenciar. Temos que nos posicionar publicamente contra essas tentativas de deslegitimação das reivindicações e de invisibilização das opressões, por exemplo, junto a organizações que atuam na proteção 
e na promoção dos direitos humanos, nos meios de comunicação, defensoria pública, entre outros.

- Implementar ações profissionais junto aos sujeitos alvo de nossas intervenções na busca da construção de estratégias coletivas para o encaminhamento de suas necessidades e demandas, condição necessária para tencionar os procedimentos e políticas institucionais, a individualização e o apassivamento.

- Conhecer, apoiar e nos articularmos às lutas dos movimentos sociais urbanos - tanto os que priorizam ações nas arenas institucionais quanto os que priorizam suas intervenções nos espaços extrainstitucionais - , pois identificar as formas de organização e de resistência desses movimentos nos possibilita dar visibilidade às disputas e contradições do processo de formulação e implementação das políticas sociais. É importante socializarmos, nesses espaços de organização, informações acerca das políticas em que atuamos, atribuindo transparência e visibilidade às situações de inexistência, oferta precária ou violação dos direitos.

- Participação nos espaços conselhistas, conferências e fóruns de reforma urbana.

- Garantir "a participação popular nas discussões no âmbito do planejamento das intervenções urbanas, conforme determina o Estatuto da Cidade, através de audiências públicas, assembleias locais, reuniões distritais" (CFESS, 2011).

- Promover estratégias de articulação entre movimentos e organizações para a troca de experiências e construção de ações conjuntas, bem como contribuir na organização de cursos de formação política para seus militantes e na sistematização e publicização das experiências organizativas e suas conquistas.

Acreditamos que essas perspectivas de intervenção e de inserção política reforçam nossa condição de sujeitos profissionais, no sentido de atuarmos para além das políticas institucionais, tencionando seus limites, publicizando a precariedade e/ou ausência de direitos e não compactuando com as estratégias de 
apassivamento, controle, criminalização e repressão das classes subalternas e de suas expressões organizativas de luta e resistência.

\section{Recebido em 28/6/2016 - Aprovado em 7/10/2016}

\section{Referências bibliográficas}

ANTUNES, R. Os sentidos do trabalho: ensaio sobre a afirmação e a negação do trabalho. São Paulo: Boitempo, 1999.

BORJA, J. As cidades e o planejamento estratégico: uma reflexão europeia e latino-americana. In: FISCHER, T. (Org.). Gestão contemporânea: cidades estratégicas e organizações locais. Rio de Janeiro: FGV, 1997.

BRITO, F. Considerações sobre a regulação armada de territórios cariocas. In:

OLIVEIRA, P. R. (Orgs.). Até o último homem. São Paulo: Boitempo, 2013.

; VILLAR, A.; BLANK, J. Será guerra? In: ; OLIVEIRA, P. R. (Orgs.). Até o último homem. São Paulo: Boitempo, 2013.

BUHL, K.; KOROL, C. Criminalização dos protestos e dos movimentos sociais. São Paulo: Instituto Rosa Luxemburg, 2008.

CHESNAIS, F. A mundialização do capital. São Paulo: Xamã, 1996.

COIMBRA, C. M. B. Operação Rio: o mito das classes perigosas - um estudo sobre a violência urbana, a mídia impressa e os discursos de segurança pública. Niterói: Intertexto, 2001.

. Direitos humanos e criminalização da pobreza. In: FREIRE, S. M. (Org.). Direitos humanos, violência e pobreza na América Latina contemporânea. Rio de Janeiro: Letra e Imagem, 2007.

DURIGUETTO, M. L. A ideologia privatista do planejamento estratégico de cidade. Libertas, Juiz de Fora, número especial, p. 68-91, jan./dez. 2004.

FARAGE, E. Experiências profissionais do Serviço Social nos movimentos sociais urbanos. In: ABRAMIDES, M. B.; DURIGUETTO, M. L. Movimentos sociais e Serviço Social: uma relação necessária. São Paulo: Cortez, 2014. 
GUIMARÃES, A. P. As classes perigosas: banditismo urbano e rural. Rio de Janeiro: Ed. da UFRJ, 2008.

GRAMSCI, A. Cadernos do cárcere. Rio de Janeiro: Civilização Brasileira, 2000.

HARVEY, D. A condição pós-moderna. São Paulo: Loyola, 1993.

LONGO, R.; KOROL, C. Criminalização dos movimentos sociais na Argentina. In: BUHL, K.; KOROL, C. Criminalização dos protestos e dos movimentos sociais. São Paulo: Instituto Rosa Luxemburg, 2008.

MANDEL, E. A crise do capital. São Paulo: Campus, Ensaio, 1990.

MARX, K. O capital: crítica da economia política - o processo de reprodução do capital. São Paulo: Nova Cultural,1985. t. 1.

MATTOS, R. C. Remoções de favelas na cidade do Rio de Janeiro: uma história do tempo presente. Outubro, n. 21, $2^{\circ}$ sem. 2013.

MOTA, A. E. (Org.). O mito da assistência social. São Paulo: Cortez, 2008.

NETTO, J. P. Crise do capital e consequências societárias. Serviço Social \& Sociedade, São Paulo, n. 111, 2012.

RAMOS, R. M. S. A intensificação do controle penal sobre a força de trabalho excedente no contexto da crise estrutural do capital. Dissertação (Mestrado em Serviço Social) — Universidade Federal de Alagoas, Maceió, 2015.

SAUER, S. Processos recentes de criminalização dos movimentos sociais populares. Brasília, set. 2008. Disponível em: <http://terradedireitos.org.br/biblioteca/salade-midia/opiniao/processosrecentes-de-criminalizacao-dos-movimentos-sociaispopulares/>. Acesso em: 22 fev. 2016.

VAINER, C. B. Pátria, empresa e mercadoria: notas sobre a estratégia discursiva do planejamento estratégico urbano. In: ; ARANTES, O.; MARICATO, E. A cidade do pensamento único: desmanchando consensos. Petrópolis: Vozes, 2000.

WACQUANT, L. As prisões da miséria. Rio de Janeiro: Zahar, 2001.

. Punir os pobres: a nova gestão da miséria nos Estados Unidos. Rio de Janeiro: Revan, 2007. 


\section{Sites e documentos pesquisados:}

CFESS Manifesta. Seminário Nacional de Serviço Social e a questão urbana no capitalismo contemporâneo. Brasília, out. 2011. Disponível em: <http://www.cfess.org. br/arquivos/cfessmanifesta2011_questaourbana >. Acesso em: 10 mar. 2016.

A tipificação de crime de terrorismo no Brasil: A perversidade da lei é a sua própria criação. Revista IHU on-line, mar. 2016. Entrevista com Adriano Pilatti. Disponível em: <www.ihu.unisinos.br/entrevistas/552134>. Acesso em: 25 mar. 2016.

Jogos olímpicos de 2016: as remoções continuam. Revista IHU on-line, 19 maio 2015. Entrevista com Alexandre Magalhães. Disponível em: <http://www.ihu.unisinos.br/ entrevistas/542728>. Acesso em: 24 nov. 2015.

Megaeventos e a mercantilização das metrópoles. Revista IHU on-line, 14 jan. 2016. Entrevista com Orlando Alves dos Santos Júnior. Disponível em: $<\mathrm{http}: / / w w w . i h u$. unisinos.br/entrevistas/550815>. Acesso em: 25 fev. 2016.

Mapa do encarceramento - Os jovens do Brasil. Brasília, 2015. Disponível em: $<$ http:// www.pnud.org.br/arquivos/encarceramento>. Acesso em: 20 jan. 2016. 